\title{
Previous Exposure to Cocaine Enhances Cocaine Self-Administration in an Alpha I-Adrenergic Receptor Dependent Manner
}

\author{
Xiang-Yang Zhang' and Therese A Kosten*,' \\ 'Division of Substance Abuse, Yale University School of Medicine, VA-CT Hospital System, West Haven, CT, USA
}

\begin{abstract}
Noradrenergic transmission is implicated in the biochemical and behavioral effects of cocaine. Recently, we demonstrated that the alpha I-adrenergic receptor antagonist prazosin attenuates cocaine-induced reinstatement of drug-seeking behavior. We now assessed whether prazosin could counter the effect of previous exposure to cocaine to enhance subsequent self-administration behavior. Rats were pre-exposed to systemic injections of either saline, prazosin $(0.3 \mathrm{mg} / \mathrm{kg})$, saline + cocaine $(10 \mathrm{mg} / \mathrm{kg})$, or prazosin + cocaine for 5 days. Starting $15-18$ days after the last pre-exposure injection, rats were trained to self-administer cocaine $(0.5 \mathrm{mg} / \mathrm{kg} / \mathrm{infusion})$ under a fixed ratio 3 (FR3) schedule of reinforcement. Several tests were conducted. First, responding for cocaine under an FR3 schedule was assessed across several doses $(0.125-1.0 \mathrm{mg} / \mathrm{kg} / \mathrm{infusion})$. Second, responding for cocaine $(0.5 \mathrm{mg} / \mathrm{kg} / \mathrm{infusion})$ under a progressive-ratio (PR) schedule was examined for 6 consecutive days. Finally, responding for cocaine $(0,0.5$, and $1.0 \mathrm{mg} / \mathrm{kg} / \mathrm{infusion})$ was determined under the PR schedule of reinforcement. Results showed that cocaine pre-exposed rats self-administer more cocaine compared to saline preexposed rats when tested under both the FR and PR schedules. Rats pre-exposed to cocaine plus prazosin did not show enhanced cocaine self-administration. These rats, as well those pre-exposed to prazosin alone, showed levels of cocaine self-administration similar to saline pre-exposed rats. Thus, previous exposure to cocaine enhanced cocaine self-administration, an effect that appears to involve activation of alpha I-adrenergic receptors. These data, along with several recent studies, show further support for the contribution of noradrenergic transmission in the behavioral effects of cocaine.
\end{abstract}

Neuropsychopharmacology (2007) 32, 638-645. doi: I 0.1038/sj.npp. I 30I I20; published online 14 June 2006

Keywords: addiction; norepinephrine; sensitization; prazosin; progressive ratio schedule; fixed ratio schedule

\section{INTRODUCTION}

Repeated intermittent exposure to cocaine and other psychostimulants results in a progressive and enduring enhancement of the behavioral and neurochemical responses to subsequent exposures, a phenomenon termed sensitization (Kalivas and Stewart, 1991; Robinson and Becker, 1986). Sensitized responses have been suggested to underlie certain aspects of cocaine and other psychostimulant addiction (Robinson and Berridge, 1993; Shippenberg and Heidbreder, 1995; Vezina et al, 2002). Consistent with this view, previous repeated exposure to cocaine or amphetamine enhances the acquisition of cocaine and amphetamine self-administration when rats were tested

*Correspondence: Dr TA Kosten, Division of Substance Abuse, Yale University School of Medicine, VA-CT Hospital System, 950 Campbell Ave., Building 5, 3rd Floor, West Haven, CT 065 I6, USA, Tel: + I 203 932 57||x5 I00, Fax: + I 203937 49|5,

E-mail: therese.kosten@yale.edu

Received 7 June 2005; revised 9 March 2006; accepted 13 March 2006 Online publication: 12 May 2006 at http://www.acnp.org/citations/ Npp05 I 206050373/default.pdf with low to moderate doses under low fixed ratio (FR) schedules of reinforcement (Horger et al, 1990; Piazza et al, 1990; Pierre and Vezina, 1997). Similar amphetamine preexposure regimens promote self-administration of higher doses when tested under a progressive ratio (PR) schedule of reinforcement as well as the reinstatement of extinguished responding for drug (Lorrain et al, 2000; Suto et al, 2002). These findings suggest that previous repeated exposure to cocaine or amphetamine enhances the rewarding or incentive motivational effects of cocaine.

The induction of behavioral sensitization to cocaine and amphetamine involves neuroadaptations in the ventral tegmental area (VTA), particularly its dopamine (DA)containing cell bodies that project to the nucleus accumbens (NAc) (Cornish and Kalivas, 2001; Vanderschuren and Kalivas, 2000; Vezina and Stewart, 1989). Indeed, the cocaine-induced increase in extracellular DA levels in NAc is an effect considered critical to its behavioral and reinforcing effects (DiChiara, 1999; Koob and Bloom, 1988; Robbins and Everitt, 1999). Yet, cocaine not only binds to the DA transporter (DAT), it also binds to norepinephrine (NE) and serotonin transporters (Florin et al, 1994; Ritz 
et al, 1987). And, by blocking the reuptake of these monoamines into presynaptic terminals, cocaine increases concentrations of these neurotransmitters at synapses in the NAc (Harris and Baldessarini, 1973; Pettit and Justice, 1989). Although much attention has been paid to alterations in the regulation of DA to understand the neurochemical bases of the behavioral effects of cocaine, DAT knockout (KO) mice self-administer cocaine intravenously (Rocha et al, 1998) and show cocaine conditioned place preference (Sora et al, 1998). Further, both cocaine and amphetamine increase extracellular levels of DA in the NAc of DAT-KO mice (Carboni et al, 2001). Thus, these results suggest that other neurotransmitters also contribute to these long-term behavioral and neurochemical effects of cocaine.

Noradrenergic transmission is implicated in the biochemical and behavioral effects of cocaine. Indeed, a number of studies in mice and rats demonstrate interactions between ascending NE and DA systems (Lategan et al, 1990; Shi et al, 2000). Increases in locomotor activity and DA levels induced by $\mathrm{D}$-amphetamine are inhibited by either systemic or local injection into the prefrontal cortex with prazosin, an alpha 1-adrenergic antagonist (Blanc et al, 1994; Darracq et al, 1998; Drouin et al, 2002; Wellman et al, 2002). Locomotor sensitization induced by cocaine, D-amphetamine, or morphine is decreased in alpha1-b subtype of adrenergic receptors $\mathrm{KO}$ mice compared to wild-type littermates (Drouin et al, 2002). Further, we have recently demonstrated that prazosin pretreatment attenuated cocaine-induced reinstatement of extinguished drugseeking behavior in rats (Zhang and Kosten, 2005). These results suggest that $\mathrm{NE}$ systems also contribute to the behavioral and neurochemical effects of cocaine.

We hypothesized that pre-exposure to cocaine would lead to a long-lasting enhancement of cocaine self-administration and that this enhancement would involve alpha 1 -adrenergic receptor activation. The purpose of the present experiment was to test this hypothesis using both FR and PR schedules of reinforcement. Testing under a FR schedule would provide information on whether cocaine pre-exposed rats would show altered sensitivity to cocaine. Testing under a PR schedule would allow us to demonstrate whether cocaine pre-exposed rats will work more to obtain the drug. The contribution of NE transmission to these effects was examined by pretreating rats with prazosin alone or in combination with cocaine.

\section{MATERIALS AND METHODS}

\section{Subjects}

Male Sprague-Dawley rats (Charles River, Wilmington, MA, USA) weighing about $300 \mathrm{~g}$ at the start of the study were used. They were housed individually in hanging, stainlesssteel cages in a temperature- and humidity-regulated vivarium on a $12 \mathrm{~h}$ light-dark cycle (lights on at 0700 hours). Food and water were freely available, except during initial lever press training for food. Procedures were approved by the Institutional Animal Care and Use Committee in strict accordance with the National Institute of Health Guide for the Care and Use of Laboratory Animals. Facilities were accredited by the American Association of Laboratory Animal Care.

\section{Drugs}

Prazosin $(0.3 \mathrm{mg} / \mathrm{kg})$ was obtained from Sigma (St Louis, MO) and cocaine hydrochloride $(10 \mathrm{mg} / \mathrm{kg})$ was obtained gratis from the National Institute on Drug Abuse (Research Triangle Institute, Research Triangle Park, NC). All drugs were mixed in $0.9 \% \mathrm{NaCl}$ and given intraperitoneally (i.p.) in a volume of $1 \mathrm{ml} / \mathrm{kg}$. Cocaine solutions for self-administration were sterile filtered and prepared fresh daily based on individual body weight that was measured daily.

\section{Groups}

Animals were randomly assigned to one of four preexposure conditions: saline-saline ( $S-S ; n=6)$, prazosin + saline $(\mathrm{P}-\mathrm{S} ; n=6)$, saline-cocaine $(\mathrm{S}-\mathrm{C} ; n=7)$, or prazosin + cocaine $(\mathrm{P}-\mathrm{C} ; n=6)$.

\section{Pre-Exposure}

Fifteen to eighteen days before catheter implant surgery, rats received a total of five sets of i.p. injections, one per day, corresponding to their pre-exposure condition: saline followed by cocaine $(10 \mathrm{mg} / \mathrm{kg} ; \mathrm{S}-\mathrm{C})$, saline followed by saline $(S-S)$, prazosin $(0.3 \mathrm{mg} / \mathrm{kg})$ followed by cocaine $(\mathrm{P}-\mathrm{C})$, or prazosin followed by saline $(\mathrm{P}-\mathrm{S})$. The first injection was administered 30 -min before the second injection.

The pretreatment time and doses of cocaine and prazosin were selected based, in part, on our previous findings (Haile et al, 2003; Zhang and Kosten, 2005). A 30-min pretreatment time was used in our prior study and also in other studies (Blanc et al, 1994; Darracq et al, 1998). In addition, the 30 -min pretreatment time is within the rise time of peak absorption with oral administration (Cavero and Roach, 1980). The dose of cocaine was selected because it is sufficient to induce sensitization of its locomotor activating effects and reinstate extinguished cocaine selfadministration behavior. The choice of prazosin dose $(0.3 \mathrm{mg} / \mathrm{kg})$ was based on our finding that higher prazosin doses $(\geqslant 0.5 \mathrm{mg} / \mathrm{kg}$ ) completely suppressed responding for food and lower doses $(\leqslant 0.3 \mathrm{mg} / \mathrm{kg})$ had minimal effects on food responding. Thus, we selected the maximal prazosin dose that did not disrupt ongoing behavior.

\section{Surgery}

Rats were implanted with chronically-indwelling catheters, made of Silastic tubing, into the right jugular vein under ketamine $(10 \mathrm{mg} / \mathrm{kg})$ and xylazine $\mathrm{HCl}(0.2 \mathrm{mg} / \mathrm{kg})$ anesthesia. Catheters passed under the skin and were threaded out of an incision made on the back. The catheter was connected to a single-guide cannula (22 G; Plastics One, Roanoke, VA) attached to a covance infusion harness (Instech Laboratories). Rats were allowed to recover for a minimum of 4 days and were treated with antibiotic during the first 3 days. The catheter was flushed at least 5 days/ week to maintain patency.

\section{Apparatus}

Standard operant conditioning chambers (Coulbourn Instruments, Allentown, PA) were housed in ventilated, sound- 
attenuating cubicles (Coulbourn) with fans to mask outside noise. As described previously (Kosten et al, 2004; Zhang and Kosten, 2005), on one wall of each chamber, there were two response levers and above each were three 'cue' lights. Minimal downward pressure (about $25 \mathrm{~g}$ ) on a lever could result in a programmed response. Between these two levers was a recessed food receptacle into which food pellets ( $45 \mathrm{mg}$ each; Bio-Serv Inc., Frenchtown, NJ) could be dispensed from a pellet dispenser. A house light was also located within the chamber. These chambers were equipped with syringe pump systems that consisted of an infusion pump (Razel model A, Stamford, CT) with a 20-ml glass syringe connected by a single channel $22 \mathrm{Ga}$ swivel and clamp (Instech Laboratories, Plymouth Meeting, PA) with Teflon tubing. The tubing was connected to the animal's catheter system in order to deliver the cocaine solution intravenously for self-administration. Experimental parameters (schedules of reinforcements, time periods, etc) were programmed using a software package (Graphic State Notation, Coulbourn) installed on a PC computer.

\section{Cocaine Self-Administration}

Before implantation of intravenous catheters, rats were food-restricted to $85 \%$ of their free-feeding body weight and allowed to lever press for food in the operant conditioning chambers. Rats were trained initially to press a lever for food pellets under a fixed ratio 1 (FR1) schedule of reinforcement overnight. Operant training for food-maintained behavior was continued until a criterion of at least 100 pellets was achieved. The animals were then returned to ad libitum food availability and implanted with jugular catheters 2 to 3 days later.

Cocaine self-administration sessions were 3-h in length and were conducted 5-7 days per week. Sessions began with the administration of two noncontingent intravenous drug infusions $(0.5 \mathrm{mg} /$ infusion, delivered over $10 \mathrm{~s})$. Rats were initially trained to lever press for cocaine $(0.5 \mathrm{mg} / \mathrm{kg} /$ infusion) under an FR1 schedule of reinforcement. One depression of the active lever resulted in a $100-\mu l$ infusion of cocaine solution delivered through the catheter over 10-s. Lever presses on the inactive lever were tabulated but had no programmed consequences. The house light was illuminated at the session onset and remained on until the active lever was depressed. The cue lights located over the active lever were illuminated during the 10-s cocaine infusion and all lights were then turned off for the subsequent 5-s time-out periods. During the infusion and time-out periods, the active lever was inactivated. Once stable response rates were seen, the schedule was switched to FR3 and continued under this schedule until responding was stable (standard deviation of the mean for 3 consecutive days was less than $20 \%$ of the mean). After this time, the experimental tests were conducted.

\section{Procedure Sequence}

The overall sequence of procedures is as follows. First, rats received their respective treatments according to their drug pre-exposure group assignment. Second, catheter surgery was performed. Third, training for cocaine self-administration behavior was conducted. Fourth, maintenance of cocaine self-administration tests conducted under the FR schedule was performed in Experiment 1. Finally, in Experiment 2 , tests were conducted under the progressive ratio for 6 consecutive days, keeping cocaine dose constant, and then rats were tested under this schedule with different cocaine doses.

Experiment 1: Cocaine dose-response tests under an FR3 schedule. Determination of the dose-response function was conducted in 3-h sessions under an FR3 schedule of reinforcement. Dose-response data were established by allowing the rat to self-administer each of four doses $(0.125$, $0.25,0.5$ and $1.0 \mathrm{mg} / \mathrm{kg} /$ infusion) on separate test sessions. Tests were run one day for each drug dose. To control for order effects, the animals were tested with the four different doses in a nonsystematic sequence. At least 2-3 days of selfadministration sessions intervened in which the training dose of cocaine was available to ensure that the animal had returned to its baseline level of responding.

Analyses of responding included tabulating numbers of self-administered infusions and inactive lever presses for each dose. Inactive lever press data served as a control for general activity levels. Data are presented as mean $( \pm$ SEM) and significance levels were set at 0.05 . These dose-response data were analyzed using a $2 \times 2 \times 4$ analysis variance (ANOVA) representing the between-group factors of cocaine pre-exposure and prazosin pre-exposure with repeated measures on dose. Post hoc comparisons between groups were made at each dose using the Newman-Keuls procedure.

Experiment 2: Cocaine responding under a PR schedule. After completion of cocaine self-administration tests under the FR3 schedule, rats were given daily access to the training dose of cocaine $(0.5 \mathrm{mg} / \mathrm{kg} /$ infusion $)$ until stable baselines of self-administration under this schedule were reestablished for at least 3 days. Subsequently, tests were conducted daily in one 6-h session per day under a PR schedule of reinforcement for 6 consecutive days with the training dose of cocaine available. Under this schedule, the response requirement for each successive injection increased by progressive increments according to the following series: $1,2,4,6,9,12,15,20,25,32,40,50,62$, $77,95,118,145,178,219,268,328,402,492$, and 603 (Richardson and Roberts, 1996). Two rats (one in the S-S group and one in the $\mathrm{S}-\mathrm{C}$ group) were not able to be run in this experiment.

After completion of 6 days of cocaine self-administration under the PR schedule, rats were allowed to self-administer either saline, $0.5 \mathrm{mg} / \mathrm{kg} /$ infusion or $1 \mathrm{mg} / \mathrm{kg} /$ infusion cocaine on separate 6-h sessions under the same PR schedule. Tests were conducted in a nonsystematic sequence. At least 2-3 days of cocaine self-administration training (FR3; $0.5 \mathrm{mg} / \mathrm{kg} /$ infusion) intervened to ensure that the animal had returned to its baseline level of responding.

The main dependent measures were the total numbers of cocaine infusions self-administered as well as final ratios completed. Final ratios completed were analyzed, not break points, because sessions were terminated at the end of $6 \mathrm{~h}$, regardless of whether rats had discontinued self-administration. We also analyzed the numbers of inactive lever 
presses emitted as a control for general activity levels. Data obtained under the PR schedule over 6 days were analyzed using a $2 \times 2 \times 6$ ANOVA representing the between-group factors of cocaine pre-exposure and Prazosin pre-exposure with repeated measures on day. Data obtained from the dose-response tests conducted under the PR schedule were analyzed using a $2 \times 2 \times 3$ ANOVA representing the between-group factors of cocaine pre-exposure and prazosin pre-exposure with repeated measures on dose. Analysis of final ratios completed were performed using the nonparametric Mann-Whitney $U$-test because these data were derived from an escalating exponential function and violate the assumption of the homogeneity of variance for ANOVA (Richardson and Roberts, 1996). Post hoc comparisons were made at each dose and day using the Newman-Keuls procedure (Winer, 1962).

\section{RESULTS}

\section{Experiment 1: Cocaine Dose-Response Tests Under an FR3 Schedule}

Responding for various cocaine doses under the fixed ratio 3 (FR3) schedule are shown in Figure 1 for the four groups of rats (S-S, S-C, P-S, and $\mathrm{P}-\mathrm{C}$ ). Rats in all groups exhibited decreasing numbers of self-administered infusions as cocaine dose increased. The effect of dose was significant, $\mathrm{F}(3,72)=71.32 ; P<0.0001$. Cocaine pre-exposure was associated with greater numbers of self-administered infusions as supported by the significant cocaine pre-exposure effect, $\mathrm{F}(1,23)=29.98 ; P<0.0001$. Cocaine pre-exposure appears to result in a steeper dose response function as seen in Figure 1 and supported by the significant cocaine pre-exposure $\times$ dose interaction, $F(3,72)=$ 16.28; $P<0.0001$. However, rats that were pretreated with

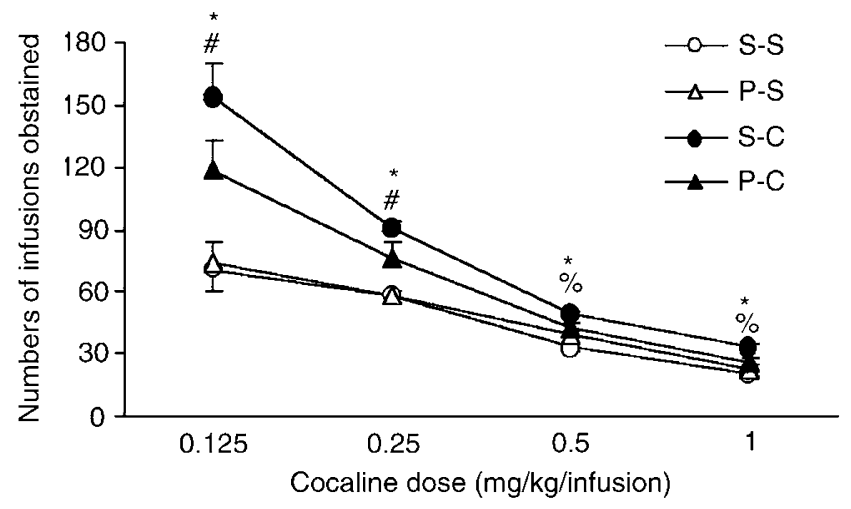

Figure I Mean $( \pm S E M)$ numbers of self-administered cocaine infusions by saline-saline ( $\mathrm{S}-\mathrm{S}$; open circles; $n=6)$, prazosin $(0.3 \mathrm{mg} / \mathrm{kg})$-saline (P-S; open diamonds; $n=6)$ saline-cocaine ( $10 \mathrm{mg} / \mathrm{kg} ; \mathrm{S}-\mathrm{C}$; closed circles; $n=7)$, and prazosin-cocaine ( $\mathrm{P}-\mathrm{C}$; closed diamonds; $n=6$ ) groups under the fixed-ratio 3 (FR3) schedule are presented by cocaine dose (mg/kg/ infusion). The S-C group (*) shows greater cocaine self-administration compared to the other three groups at all four doses $(P<0.05)$. The $P-C$ group (\#) shows greater self-administration than the $\mathrm{S}-\mathrm{S}$ and $\mathrm{P}-\mathrm{S}$ groups at the 0.125 and $0.25 \mathrm{mg} / \mathrm{kg}$ cocaine doses $(P<0.05)$ and the $P-C$ group (\%) shows greater self-administration than the $\mathrm{S}-\mathrm{S}$ group at the 0.5 and $1.0 \mathrm{mg} / \mathrm{kg}$ doses $(P<0.05)$. All other group and dose comparisons are not significant. prazosin before cocaine injections (P-C) did not selfadminister as much cocaine as the rats that were pretreated with saline before cocaine injections $(\mathrm{S}-\mathrm{C})$. This statement is supported by the significant interaction of cocaine preexposure $\times$ prazosin pre-exposure, $\mathrm{F}(1,23)=4.33 ; P<0.05$. On the other hand, prazosin pre-exposure itself did not have any significant effect on cocaine self-administration as the main effect of prazosin pre-exposure failed to reach significance $(P>0.10)$. Post hoc comparisons revealed that the $S-C$ group showed significantly greater cocaine selfadministration compared to the other three groups at all four doses $(P<0.05)$. The $\mathrm{P}-\mathrm{C}$ group shows greater selfadministration than the S-S and P-S groups at the 0.125 and $0.25 \mathrm{mg} / \mathrm{kg}$ cocaine doses $(P<0.05)$ and the $\mathrm{P}-\mathrm{C}$ group shows greater self-administration than the $\mathrm{S}-\mathrm{S}$ group at the 0.5 and $1.0 \mathrm{mg} / \mathrm{kg}$ doses $(P<0.05)$. All other group and dose comparisons are not significant.

Numbers of inactive lever presses emitted under the FR3 schedule of reinforcement across cocaine doses are presented in Table 1A. There are no significant main effects or interactions of prazosin or cocaine pre-exposures on numbers of inactive lever presses that were minimal across doses $(P>0.10)$.

Table I Mean $( \pm$ SEM) Inactive Lever Presses for Rats Pre-Exposed to Saline $(\mathrm{S}-\mathrm{S})$, Prazosin $(0.3 \mathrm{mg} / \mathrm{kg})$ and Saline $(\mathrm{P}-\mathrm{S})$, Saline and Cocaine $(10 \mathrm{mg} / \mathrm{kg} ; \mathrm{S}-\mathrm{C})$, and Prazosin and Cocaine $(\mathrm{P}-\mathrm{C})$

(a) Inactive lever presses by cocaine dose for FR dose-response tests

Cocaine dose (mg/kg/infusion)

\begin{tabular}{|c|c|c|c|c|}
\hline Group & 0.125 & 0.25 & 0.5 & I \\
\hline$S-S$ & $0.5(0.3)$ & $0.7(0.5)$ & $0.3(0.2)$ & $1.5(1.0)$ \\
\hline P-S & $1.0(0.5)$ & $0.2(0.2)$ & $0.3(0.2)$ & $0.2(0.2)$ \\
\hline$S-C$ & $1.4(0.7)$ & $0.3(0.2)$ & $0.3(0.3)$ & I.I (0.6) \\
\hline $\mathrm{P}-\mathrm{C}$ & $0.7(0.3)$ & $0.3(0.3)$ & $0.7(0.7)$ & $0.3(0.2)$ \\
\hline
\end{tabular}

(b) Inactive lever presses by day for progressive-ratio tests

Day

\begin{tabular}{lcccccc}
\cline { 2 - 7 } Group & $\mathbf{I}$ & $\mathbf{2}$ & $\mathbf{3}$ & $\mathbf{4}$ & $\mathbf{5}$ & $\mathbf{6}$ \\
\hline S-S & $9.8(3.9)$ & $4.0(1.3)$ & $7.5(2.7)$ & $9.0(3.8)$ & $4.0(1.8)$ & $5.5(2.3)$ \\
P-S & $9.0(2.3)$ & $7.7(2.4)$ & $7.8(1.7)$ & $8.5(2.2)$ & $8.5(3.9)$ & $7.5(2.1)$ \\
S-C & $9.3(2.7)$ & $9.5(2.8)$ & $8.3(2.9)$ & $8.8(2.9)$ & $8.2(1.9)$ & $8.3(2.6)$ \\
P-C & $5.3(2.8)$ & $5.8(1.8)$ & $7.7(1.7)$ & $6.3(3.0)$ & $5.0(1.9)$ & $6.3(2.4)$
\end{tabular}

(c) Inactive lever presses by cocaine dose for progressive-ratio dose response tests

Cocaine dose (mg/kg/infusion)

\begin{tabular}{lccc} 
Group & $\mathbf{0}$ & $\mathbf{0 . 5}$ & $\mathbf{I}$ \\
\cline { 2 - 4 } & & & \\
\hline S-S & $7.8(4.7)$ & $3.4(0.9)$ & $4.4(2.5)$ \\
P-S & $10.2(3.3)$ & $8.5(3.9)$ & $9.0(1.8)$ \\
S-C & $7.3(1.9)$ & $8.7(2.8)$ & $7.0(2.8)$ \\
P-C & $6.3(3.0)$ & $5.0(1.9)$ & $6.3(2.4)$ \\
\hline
\end{tabular}




\section{Experiment 2: Cocaine Responding Under a PR Schedule}

Responding for cocaine $(0.5 \mathrm{mg} / \mathrm{kg} /$ infusion) under a PR schedule across 6 consecutive days are shown in Figure 2 for the four groups of rats $(\mathrm{S}-\mathrm{S}, \mathrm{S}-\mathrm{C}, \mathrm{P}-\mathrm{S}$, and $\mathrm{P}-\mathrm{C})$. Cocaine pre-exposure was associated with greater numbers of self-administered infusions as supported by the significant cocaine pre-exposure effect, $F(1,21)=17.16$; $P<0.001$. Prazosin pre-exposure blocked this enhancement in responding for cocaine by cocaine pre-exposure as evidenced by the significant main effect of prazosin preexposure, $\mathrm{F}(1,21)=5.35 ; P<0.05$. Further, the interaction of cocaine and prazosin pre-exposure effects was significant, $\mathrm{F}(1,21)=8.12 ; P<0.01$. Post hoc comparisons indicate that the $\mathrm{S}-\mathrm{C}$ group self-administered more cocaine on all 6 days compared to the other three groups $(P<0.05)$.

Data on final ratios completed across days are presented in Table $2 \mathrm{a}$ for the four groups of rats $(\mathrm{S}-\mathrm{S}, \mathrm{S}-\mathrm{C}, \mathrm{P}-\mathrm{S}$, and $\mathrm{P}-\mathrm{C})$. The $\mathrm{S}-\mathrm{C}$ group that was pre-exposed to cocaine showed greater cocaine self-administration compared to the other three groups across all 6 days $(P<0.05)$.

Numbers of inactive lever presses emitted under the PR schedule of reinforcement across days are presented in Table 1b. There were no significant main effects or interactions of prazosin or cocaine pre-exposures on numbers of inactive lever presses that were minimal across doses $(P>0.10)$.

Responding for various doses of cocaine under the PR schedule are shown in Figure 3. Minimal self-administered infusions were seen when saline $(0 \mathrm{mg} / \mathrm{kg})$ was available for delivery and numbers of self-administered infusions increased when cocaine $(0.5$ and $1.0 \mathrm{mg} / \mathrm{kg})$ was available. This is supported by the significant dose effect, $F(2,42)=$ $142.45 ; P<0.0001$. Again, cocaine pre-exposure was associated with enhanced responding as supported by the significant cocaine pre-exposure effect, $\mathrm{F}(1,21)=12.74 ; P<0.01$, and by its significant interaction with dose, $\mathrm{F}(2,42)=20.33$; $P<0.0001$. Prazosin pre-exposure eliminated the enhancement in responding due to cocaine pre-exposure as supported by the significant main effect of prazosin,

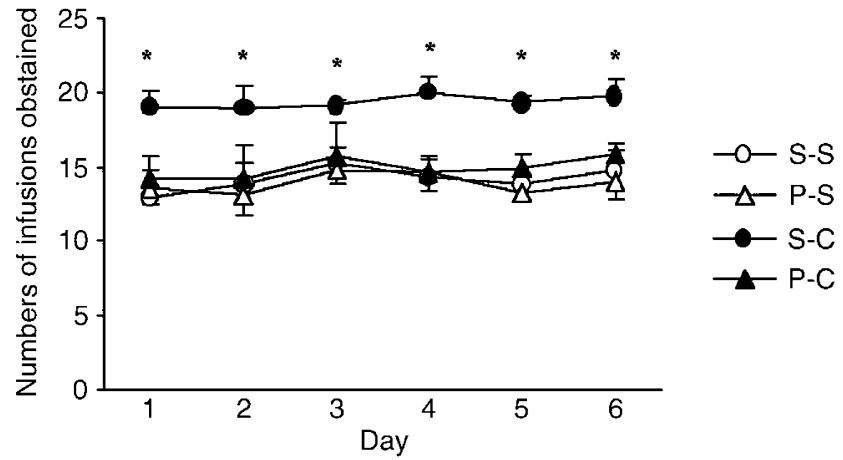

Figure 2 Mean $( \pm S E M)$ numbers of self-administered cocaine infusions by saline-saline (S-S; open circles; $n=5)$, prazosin $(0.3 \mathrm{mg} / \mathrm{kg})$-saline $(P-S$; open diamonds; $n=6)$, saline-cocaine $(10 \mathrm{mg} / \mathrm{kg} ; \mathrm{S}-\mathrm{C}$; closed circles; $n=6$ ), and prazosin-cocaine ( $\mathrm{P}-\mathrm{C}$; closed diamonds; $n=6$ ) groups under the PR schedule for 6 consecutive days are presented. The cocaine dose available for delivery was $0.5 \mathrm{mg} / \mathrm{kg} /$ infusion on all 6 days in 6 -h sessions. The S-C group (*) shows greater cocaine self-administration compared to the other three groups across all 6 days $\left(P^{\prime} s<0.05\right)$. All other group and dose comparisons are not significant.
$\mathrm{F}(1,21)=4.83 ; P<0.05$, and its interaction with cocaine pre-exposure, $\mathrm{F}(1,21)=13.17 ; P<0.005$. Post hoc comparisons indicate that the $\mathrm{S}-\mathrm{C}$ group showed significantly greater self-administration than the other three groups at both the 0.5 and $1.0 \mathrm{mg} / \mathrm{kg} /$ infusion doses $(P<0.001)$.

Data on final ratios completed across doses are presented in Table $2 b$ for the four groups of rats $(\mathrm{S}-\mathrm{S}, \mathrm{S}-\mathrm{C}, \mathrm{P}-\mathrm{S}$, and $\mathrm{P}-\mathrm{C})$. The $\mathrm{S}-\mathrm{C}$ group that was pre-exposed to cocaine showed greater cocaine self-administration compared to the other three groups when cocaine was available for delivery $(P<0.05)$.

Table 2 Median Final Ratios Completed Under the PR Schedule are Presented for Rats Pre-Exposed to Saline (S-S), Prazosin $(0.3 \mathrm{mg} / \mathrm{kg})$ and Saline $(P-S)$, Saline and Cocaine $(10 \mathrm{mg} / \mathrm{kg} ; \mathrm{S}-\mathrm{C})$, and Prazosin and Cocaine $(\mathrm{P}-\mathrm{C})$

(a) Final ratios completed by day for PR tests

\begin{tabular}{lrrrrrr} 
& \multicolumn{7}{c}{ Day } \\
\cline { 2 - 7 } Group $^{\mathbf{a}}$ & $\mathbf{I}$ & $\mathbf{2}$ & $\mathbf{3}$ & $\mathbf{4}$ & $\mathbf{5}$ & $\mathbf{6}$ \\
\hline S-S & 62 & 77 & 95 & 95 & 62 & 77 \\
$\mathrm{P}-\mathrm{S}$ & 77 & 95 & 95 & 95 & 95 & 118 \\
$\mathrm{~S}-\mathrm{C}$ & 219 & 219 & 328 & 328 & 219 & 328 \\
$\mathrm{P}-\mathrm{C}$ & 77 & 77 & 77 & 77 & 62 & 77
\end{tabular}

(b) Final ratios completed by cocaine dose for PR dose-response tests

Cocaine dose (mg/kg/infusion)

\begin{tabular}{lrrr}
\cline { 2 - 4 } Group $^{\mathbf{a}}$ & $\mathbf{0}$ & $\mathbf{0 . 5}$ & $\mathbf{1 . 0}$ \\
\hline S-S & 12 & 77 & 62 \\
P-S & 9 & 77 & 95 \\
S-C & 15 & 219 & 328 \\
P-C & 15 & 62 & 77
\end{tabular}

${ }^{\mathrm{a}}$ Significant group effect (S-C > other groups).

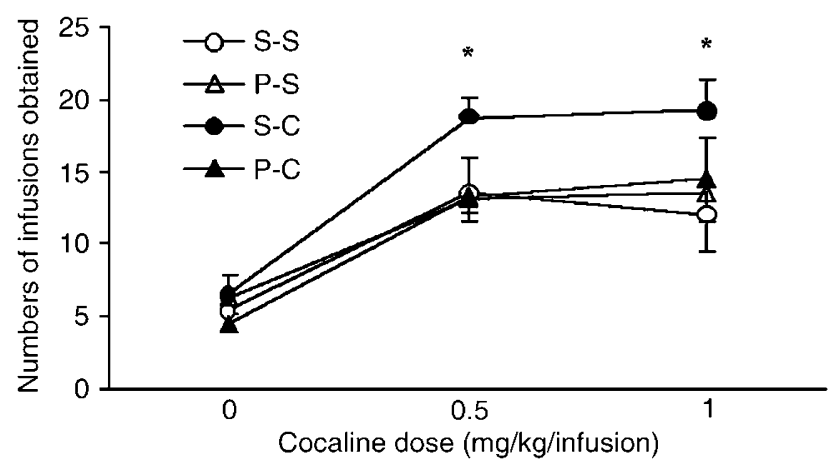

Figure 3 Mean $( \pm S E M)$ numbers of self-administered cocaine infusions by saline-saline (S-S; open circles; $n=5)$, prazosin $(0.3 \mathrm{mg} / \mathrm{kg})$-saline (P-S; open diamonds; $n=6)$, saline-cocaine $(10 \mathrm{mg} / \mathrm{kg} ; \mathrm{S}-\mathrm{C}$; closed circles; $n=6$ ), and prazosin-cocaine (P-C; closed diamonds; $n=6$ ) groups under the PR schedule are presented by cocaine dose ( $\mathrm{mg} / \mathrm{kg} /$ infusion). Test sessions were 6-h in length. The S-C group (*) shows greater cocaine selfadministration compared to the other three groups at the 0.5 and $1.0 \mathrm{mg} /$ $\mathrm{kg} /$ infusion doses $(P<0.00 \mathrm{I})$. All other group and dose comparisons are not significant. 
Numbers of inactive lever presses emitted under the PR schedule of reinforcement across cocaine doses are presented in Table 1c. There were no significant main effects or interactions of prazosin or cocaine pre-exposures on numbers of inactive lever presses that were minimal across doses $(P>0.10)$.

\section{DISCUSSION}

In the present study, we demonstrate that pre-exposure to cocaine enhances maintenance of cocaine self-administration under both FR and PR schedules. We also show that this facilitation of cocaine self-administration behavior involves activation of alpha 1-adrenergic receptors. Pharmacological blockade of these receptors with the alpha 1-adrenergic antagonist, prazosin, during cocaine pre-exposure attenuates or prevents this facilitation. Attenuation of heightened responding for cocaine by prazosin co-treatment with cocaine is seen under the FR schedule, whereas a blockade of this effect is seen under the PR schedule. Yet, pre-exposure to prazosin alone had no effect on rats' subsequent self-administration of cocaine under either schedule of reinforcement. Hence, our findings suggest that activation of alpha 1-adrenergic receptors plays an important role in the induction of sensitization by cocaine to its subsequent enhancement of cocaine self-administration.

Cocaine pre-exposure facilitated maintenance of cocaine self-administration behavior but did not alter inactive lever press responding, indicating a specific effect on cocaine reinforcement. These findings of the present study are largely consistent with previous studies. Prior studies report that drug pre-exposure enhanced acquisition of selfadministration of cocaine (Horger et al, 1990) and amphetamine (Piazza et al, 1990) under conditions of low to moderate test doses and low FR schedules. The enhancement of cocaine self-administration by cocaine pre-exposure was observed in the present study under maintenance conditions across a wide dose range with a modest FR3 schedule. Further, cocaine self-administration behavior was facilitated when rats were required to work progressively more for each successive cocaine infusion under the PR schedule of reinforcement (Richardson and Roberts, 1996). And, this latter effect was seen with moderate to high cocaine doses. Similarly, previous studies report that responding for amphetamine or cocaine is enhanced under a PR schedule by amphetamine pre-exposure (Lorrain et al, 2000; Mendrek et al, 1998; Suto et al, 2002). However, amphetamine pre-exposure did not facilitate responding under an FR schedule, unlike the results of the present study (Lorrain et al, 2000; Suto et al, 2002). Differences in preexposure drugs and pretreatment regimens, test doses, and schedules of reinforcement between the prior studies and the present study may contribute to the discrepancy. That is, we tested multiple doses of cocaine under an FR3 schedule, whereas the prior studies tested one dose of amphetamine or cocaine under FR1 and FR2 schedules. Nonetheless, the present study adds to the literature showing that drug pre-exposure facilitates subsequent drug selfadministration by demonstrating this effect with cocaine pre-exposure and cocaine self-administration under maintenance conditions. Enhanced self-administration observed following pre-exposure may reflect cocaine-induced sensitization that can be presumed to model psychostimulant addiction, as suggested before (Robinson and Berridge, 1993).

The facilitation of self-administration behavior seen in the present and prior studies may reflect augmentation of drug-induced increases in NAc DA levels. Repeated exposure to cocaine augments the NAc DA responses to cocaine (Kalivas and Duffy, 1990; Zapata et al, 2003) and NAc DA has been linked to the reinforcing effects of cocaine (Bergman et al, 1989; Ritz et al, 1987). Increased NAc DA levels induced by prior drug exposure have also been linked to increases in the locomotor activating effects of amphetamine and cocaine (Kalivas and Stewart, 1991; Robinson and Becker, 1986). It is generally thought that the sensitization induced by psychostimulants involves changes in DA transmission from VTA to NAc (Cornish and Kalivas, 2001; Vanderschuren and Kalivas, 2000; Vezina and Stewart, 1989). Similarly, DA transmission in the VTA-NAc pathway contributes to the ability of repeated amphetamine exposure to facilitate self-administration behavior (Suto et al, 2002). Data from the present study suggest that, in addition to DA, NE transmission contributes to the facilitation of self-administration by prior drug exposure because pretreatment with the alpha 1-adrenergic antagonist, prazosin, decreased this effect.

The ability of prazosin to attenuate or block the effects of cocaine pre-exposure to enhance self-administration behavior suggests that alpha 1-adrenergic receptors contribute to the development of cocaine-induced sensitization. However, the mechanisms by which this occurs are not known. Nonetheless, numerous studies show that NE and DA systems interact and that this may occur via stimulation of alpha 1-adrenergic receptors. Systemic or local administration of prazosin into the prefrontal cortex blocks increased DA and locomotor responses induced by systemic D-amphetamine (Darracq et al, 1998). Prazosin decreased spontaneous bursting of VTA DA cells (Grenhoff and Svensson, 1993), whereas direct application of an alpha 1-adrenergic receptor agonist, phenylephrine, in brain slices, depolarized some cells (Grenhoff et al, 1995). Increases burst firing of VTA DA cells was induced by systemic administration of reboxetin, a specific inhibitor of the NE transporter (Linner et al, 2001). In fact, Shi et al (2000) suggest that $\mathrm{D}$-amphetamine has two effects on DA cells; a DA-mediated inhibition and a non-DA-mediated excitation, with the latter thought to act through alpha 1-adrenergic receptors.

Stimulation of cortical alpha 1-adrenergic receptors by systemic D-amphetamine may facilitate DA transmission in the NAc through a cortico-VTA glutamatergic pathway that would drive VTA dopaminergic cells into a bursting activity (Darracq et al, 1998). The inhibitory properties of prazosin on D-amphetamine-induced increases in extracellular DA levels in the NAc and in locomotor activity may reflect inhibition of the activity of glutamatergic excitatory cortical neurons bearing D1 receptors and projecting directly or indirectly through the NAc to the VTA (Karreman and Moghaddam, 1996). Moreover, activation of a glutamatergic projection from the prefrontal cortex to the NAc underlies cocaine-primed reinstatement of drug-seeking behavior (McFarland et al, 2004). A recent electrophysiological study 
also shows that the NE system could serve to alter the reward value of stimuli that have significant effects on DA neuron firing patterns through mGluRs. Decreased alphaadrenoceptor regulation of the mGlu-R-mediated current may be a cellular mechanism associated with effects of withdrawal from cocaine after repeated drug administration (Paladini et al, 2004). Taken together, these findings suggest that alpha 1-adrenergic transmission may regulate the behavioral effects of psychostimulants by influencing glutamatergic systems or its interaction with DA systems. The results from the present study along with data from our recent investigation showing that prazosin-attenuated cocaine-induced reinstatement of drug-seeking behavior show strong support for the contribution of NE to the motivational effects of cocaine (Zhang and Kosten, 2005).

While the data from the present study along with our prior study suggest that alpha 1-adrenoreceptors contribute to the motivational effects of cocaine, there are some limitations. Prazosin was administered systemically and only one dose was tested. However, we utilized the maximal dose that did not disrupt ongoing behavior based on our prior study. In the present study, pretreatment with this dose resulted in maximal effects under the $P R$ schedule tests and less than maximal, but significant, effects under the FR schedule tests. Second, while the tests under the FR schedule suggest that prazosin attenuates the ability of cocaine preexposure to facilitiate self-administration, it is difficult to interpret shifts in dose-response curves under FR schedules of reinforcement (Mello and Negus, 1996). In fact, the increase in responding in the cocaine pre-exposed group could be interpreted as an increase in tolerance to the reinforcing effects of cocaine. Yet, prazosin also blocked the ability of cocaine pre-exposure to enhance responding for cocaine under the PR schedule of reinforcement. Finally, that we did not test responding for saline under an FR3 schedule of reinforcement poses a slight limitation in the study. However, there was no effect of prazosin pretreatment on responding for saline under the PR experiment. Further, we typically find that response levels are minimal when saline is available for delivery and thus would likely not provide a sensitive test of the effects of prazosin pretreatment with cocaine. Nonetheless, it is unlikely that nonspecific effects of prazosin contributed to the effects seen in the present study. There were no effects of prazosin on inactive lever press responding in this study and we previously showed that the prazosin dose chosen did not disrupt ongoing operant responding for food or affect responding for saline (Zhang and Kosten, 2005). Although the mechanisms that underlie the ability of prazosin to attenuate the facilitation of cocaine self-administration by prior cocaine exposure remain to be elucidated, data from our studies point to the role of $\mathrm{NE}$ in the motivational effects of cocaine.

\section{ACKNOWLEDGEMENTS}

This research was supported by a VA Merit Grant.

\section{REFERENCES}

Bergman J, Madras BK, Johnson SE, Spealman RD (1989). Effects of cocaine and related drugs in nonhuman primates. III: self- administration by squirrel monkeys. J Pharmacol Exper Therap 251: $150-155$.

Blanc G, Trovero F, Vezina P, Herve D, Godeheu AM, Glowinski J et al (1994). Blockade of prefronto-cortical alpha 1-adrenergic receptors prevents locomotor hyperactivity induced by subcortical D-amphetamine injection. Eur J Neurosci 6: 293-298.

Carboni E, Spielewoy C, Vacca C, Nosten-Bertrand M, Giros B, DiChiara G (2001). Cocaine and amphetamine increase extracellular dopamine in the nucleus accumbens of mice lacking the dopamine transporter gene. J Neurosci 21: RC141:1-5.

Cavero I, Roach AG (1980). The pharmacology of prazosin, a novel antihypertensive agent. Life Sci 27: 1525-1540.

Cornish JL, Kalivas PW (2001). Repeated cocaine administration into the rat ventral tegmental area produces behavioral sensitization to a systemic cocaine challenge. Behav Brain Res 126: 205-209.

Darracq L, Blanc G, Glowinski J, Tassin JP (1998). Importance of the noradrenaline-dopamine coupling in the locomotor activating effects of D-amphetamine. J Neurosci 18: 2729-2739.

DiChiara G (1999). Drug addiction as dopamine-dependent associative learning disorder. Eur J Pharmacol 375: 13-30.

Drouin C, Darracq L, Trovero F, Blanc G, Glowinski J, Cotecchia S et al (2002). $\alpha$-1b-Adrenergic receptors control locomotor and rewarding effects of psychostimulants and opiates. J Neurosci 22: 2873-2884.

Florin SM, Kuczenski R, Segal DS (1994). Regional extracellular norepinephrine responses to amphetamine and cocaine and effects of clonidine pretreatment. Brain Res 654: 53-62.

Grenhoff J, North RA, Johnson SW (1995). Alpha 1-adrenergic effects on dopamine neurons recorded intracellularly in the rat midbrain slice. Eur J Neurosci 7: 1707-1713.

Grenhoff J, Svensson TH (1993). Prazosin modulates the firing pattern of dopamine neurons in rat ventral tegmental area. Eur J Pharmacol 233: 79-84.

Haile CN, During MJ, Jatlow PI, Kosten TR, Kosten TA (2003). Disulfiram facilitates the development and expression of locomotor sensitization to cocaine in rats. Biol Psychiat 54: 915-921.

Harris JE, Baldessarini RJ (1973). Uptake of [ $\left.{ }^{3} \mathrm{H}\right]$-catecholamines by homogenates of rat corpus striatum and cerebral cortex: effects of amphetamine analogues. Neuropharmacology 12: 659-679.

Horger BA, Shelton K, Schenk S (1990). Preexposure sensitizes rats to the rewarding effects of cocaine. Pharmacol Biochem Behav 37: 707-711.

Kalivas PW, Duffy P (1990). Effect of acute and daily cocaine treatment on extracellular dopamine in the nucleus accumbens. Synapse 5: 48-58.

Kalivas PW, Stewart J (1991). Dopamine transmission in the initiation and expression of drug- and stress-induced sensitization of motor activity. Brain Res Rev 16: 223-244.

Karreman M, Moghaddam B (1996). Effect of a pharmacological stressor on glutamate efflux in the prefrontal cortex. Brain Res 716: $180-182$.

Koob GF, Bloom FE (1988). Cellular and molecular mechanisms of drug dependence. Science 242: 715-723.

Kosten TA, Sanchez H, Zhang XY, Kehoe P (2004). Neonatal isolation enhances acquisition of cocaine self-administration and food responding in female rats. Behav Brain Res 151: 137-149.

Lategan AJ, Marien MR, Colpaert FC (1990). Effects of locus coeruleus lesions on the release of endogenous dopamine in the rat nucleus accumbens and caudate nucleus as determined by intracerebral microdialysis. Brain Res 523: 134-138.

Linner L, Endersz H, Ohman D, Bengtsson F, Schalling $M$, Svensson TH (2001). Reboxetine modulates the firing pattern of dopamine cells in the ventral tegmental area and selectively increases dopamine availability in the prefrontal cortex. J Pharmacol Exp Therap 297: 540-546. 
Lorrain DS, Arnold GM, Vezina P (2000). Previous exposure to amphetamine increases incentive to obtain the drug: long-lasting effects revealed by the progressive ratio schedule. Behav Brain Res 107: 9-19.

McFarland K, Davidge SB, Lapish CC, Kalivas PW (2004). Limbic and motor circuitry underlying footshock-induced reinstatement of cocaine-seeking behavior. J Neurosci 24: 1551-1560.

Mello NK, Negus SS (1996). Preclinical evaluation of pharmacotherapies for treatment of cocaine and opioid abuse using drug self-administration procedures. Neuropsychopharmacology 14: 375-424.

Mendrek A, Blaha CD, Phillips AG (1998). Pre-exposure of rats to amphetamine sensitized self-administration of this drug under a progressive ratio schedule. Psychopharmacology 135: 416-422.

Paladini CA, Mitchell JM, Williams JT, Mark GP (2004). Cocaine self-administration selectively decreases noradrenergic regulation of metabotropic glutamate receptor-mediated inhibition in dopamine neurons. J Neurosci 24: 5209-5215.

Pettit HO, Justice JB (1989). Dopamine in the nucleus accumbens during cocaine self-administration as studied by in vivo microdialysis. Pharmacol Biochem Behav 34: 899-904.

Piazza PV, Deminiere J-M, LeMoal M, Simon H (1990). Stress- and pharmacologically-induced behavioral sensitization increases vulnerability to acquisition of amphetamine self-administration. Brain Res 514: 22-26.

Pierre PJ, Vezina P (1997). Predisposition to self-administer amphetamine: the contribution of response to novelty and prior exposure to the drug. Psychopharmacology 129: 277-284.

Richardson NR, Roberts DC (1996). Progressive ratio schedules in drug self-administration studies in rats: a method to evaluate reinforcing efficacy. J Neurosci Met 66: 1-11.

Ritz MC, Lamb RJ, Goldberg SR, Kuhar MJ (1987). Cocaine receptors on dopamine transporters are related to self-administration of cocaine. Science 237: 1219-1223.

Robbins TW, Everitt BJ (1999). Drug addiction: bad habits add up. Nature 398: 567-570.

Robinson TE, Becker JB (1986). Enduring changes in brain and behavior produced by chronic amphetamine administration: a review and evaluation of animal models of amphetamine psychosis. Brain Res Rev 11: 157-198.

Robinson TE, Berridge KC (1993). The neural basis of drug craving: an incentive sensitization theory of addiction. Brain Res Rev 18: 247-291.
Rocha BA, Fumagalli F, Gainetdinov RR, Jones SR, Ator R, Giros B et al (1998). Cocaine self-administration in dopamine-transporter knockout mice. Nat Neurosci 1: 132-137.

Shi WX, Pun CL, Zhang XX, Jones MD, Bunney BS (2000). Dual effects of D-amphetamine on dopamine neurons mediated by dopamine and nondopamine receptors. J Neurosci 20: 3504-3511.

Shippenberg TS, Heidbreder C (1995). Sensitization to the conditioned rewarding effects of cocaine: pharmacological and temporal characteristics. J Pharmacol Exper Therap 273: 808-815.

Sora I, Wichems C, Takahashi N, Li XF, Zeng Z, Revay R et al (1998). Cocaine reward models: conditioned place preference can be established in dopamine- and in serotonin-transporter knockout mice. Proc Nat Acad Sci 95: 7699-7704.

Suto N, Austin JD, Tanabe LM, Kramer MK, Wright DA, Vezina P (2002). Previous exposure to VTA amphetamine enhances cocaine self-administration under a progressive ratio schedule in a D1 dopamine receptor dependent manner. Neuropsychopharmacology 27: 970-979.

Vanderschuren LJMJ, Kalivas PW (2000). Alterations in dopaminergic and glutamatergic transmission in the induction and expression of behavioral sensitization: a critical review of preclinical studies. Psychopharmacology 151: 99-120.

Vezina P, Lorrain DS, Arnold GM, Austin JD, Suto N (2002). Sensitization of midbrain dopamine neuron reactivity promotes the pursuit of amphetamine. J Neurosci 22: 4654-4662.

Vezina P, Stewart J (1989). The effect of dopamine receptor blockade on the development of sensitization to the locomotor activating effects of amphetamine and morphine. Brain Res 499: $108-120$.

Wellman P, Ho D, Cepeda-Benito A, Bellinger L, Nation J (2002). Cocaine-induced hypophagia and hyperlocomotion in rats are attenuated by prazosin. Eur J Pharmacol 455: 117-126.

Winer BJ (1962). Statistical Principles in Experimental Design. McGraw-Hill: New York.

Zapata A, Chefer VI, Ator R, Shippenberg TS, Rocha BA (2003). Behavioural sensitization and enhanced dopamine response in the nucleus accumbens after intravenous cocaine self-administration in mice. Eur J Neurosci 17: 590-596.

Zhang XY, Kosten TA (2005). Prazosin, an $\alpha-1$ adrenergic antagonist, reduces cocaine-induced reinstatement of drugseeking. Biol Psychiatry 57: 1202-1204. 